\title{
Baerveldt implant for secondary glaucoma due to iris melanoma
}

This article was published in the following Dove Press journal:

Clinical Ophthalmology

30 April 2010

Number of times this article has been viewed

\author{
Annelie N Tan' \\ Juliette GMM Hoevenaars' \\ Carroll AB Webers' \\ Bertil Damato ${ }^{2}$ \\ Henny JM Beckers' \\ 'University Eye Clinic, Maastricht, \\ The Netherlands; ${ }^{2}$ Ocular Oncology \\ Service Royal Liverpool University \\ Hospital, Liverpool, United Kingdom
}

Correspondence: Annelie NTan University Eye Clinic Maastricht, PO Box 5800, 6202AZ Maastricht, The Netherlands

$\mathrm{Tel}+3$ I 433875342

Fax +3I 433875343

Email a.tan@mumc.nl
Background: Proton beam therapy (PBT) is effective in the treatment of iris melanoma. Reported complications after PBT are radiation-induced cataract and raised intraocular pressure (IOP). Filtering glaucoma surgery has generally been avoided because of fears of seeding.

Case report: A 37-year-old man presented with a self-discovered, pigmented lesion on his right iris. Four years later, the pigmented lesion was diagnosed as an iris melanoma, because of documented growth. The patient was treated with PBT but developed secondary glaucoma one month later. The IOP could not be controlled despite maximal medical therapy and selective laser trabeculoplasty (SLT). Finally, Baerveldt implant surgery was performed, resulting in an IOP lowering to $10 \mathrm{mmHg}$ and stabilization of the glaucomatous visual field loss.

Conclusion: Our case demonstrates that Baerveldt implant surgery is a reasonable therapy for glaucoma following successful radiotherapy of iris melanoma.

Keywords: iris melanoma, proton beam therapy, secondary glaucoma, Baerveldt implant surgery

\section{Introduction}

Iris melanoma comprises $3 \%$ to $10 \%$ of all uveal melanomas and is the most common primary malignancy of the iris. ${ }^{1,2}$ It tends to have a ten-year metastasis rate of $3 \%$ to $6 \%{ }^{1-3}$ Possible therapies for iris melanoma include iridectomy, iridocyclectomy, plaque brachytherapy, proton beam therapy (PBT), and enucleation. PBT is generally selected if the tumor is too extensive for surgical excision or if such surgery is rejected because the surgical iris coloboma is expected to cause unacceptable photophobia or cosmetic deficit. The main complications after PBT are radiation-induced cataract and raised IOP. Trabecular scarring may play a role in the latter. ${ }^{4}$ Secondary glaucoma occurs in $7 \%$ of eyes with untreated iris melanoma and in $30 \%$ of patients with microscopically-confirmed iris melanoma, occurring mostly because of tumor infiltration of the trabecular meshwork with outflow obstruction. ${ }^{5,6}$ Traditionally, filtering glaucoma surgery has been avoided in patients with iris melanoma because of fears that such aqueous drainage might encourage subconjunctival or intraorbital tumor seeding., ${ }^{2,3}$ Nevertheless, insights into the biology of uveal melanomas and outcome studies after PBT encouraged us to treat a patient with a Baerveldt tube implantation because of rapidly deteriorating vision and uncontrollable glaucoma.

\section{Case report}

A 37-year-old man discovered a pigmented iris lesion in his right eye. The bestcorrected visual acuity (BCVA) was 6/6. Ophthalmologic examination showed a 
pigmented iris lesion between the 5.30 and 6.30 o'clock meridians with a basal diameter of $3.5 \mathrm{~mm}$ and a thickness of $1.4 \mathrm{~mm}$. Gonioscopy showed pigment deposition in the inferior and nasal parts of the iridocorneal angle. The IOP was $25 \mathrm{mmHg}$. Ultrasonography showed no involvement of the ciliary body. The left eye was normal. Initially, the tumor showed no growth; however, four years after presentation, the iris lesion had changed to a diffuse tumor, extending from the 4.30 to 6.30 o'clock meridians with seeding onto the iris surface from the 3.30 to 7.00 o'clock meridians. The pupil also became oval (Figure 1a). Gonioscopy showed pigment deposition in the iridocorneal angle between the 1.00 and 10.00 o'clock meridians. The BCVA decreased to $6 / 7.5$. The patient refused a biopsy for histological examination. Because of documented growth, the tumor was diagnosed as an iris melanoma.

The entire anterior segment was treated with PBT (53.1 Gy, administered in four fractions over four days). One month later (Figures $1 \mathrm{~b}$ and $1 \mathrm{c}$ ) the patient developed secondary glaucoma with IOP levels fluctuating between 20 and $43 \mathrm{mmHg}$, despite maximal medical therapy. The optic disc showed normal cupping.

SLT was performed, placing 25 shots with a total energy of $15 \mathrm{~mJ}$ in the nasal quadrant. The IOP decreased slightly but only transiently. Further treatment of the temporal quadrant did not lead to a reduction of IOP. Meanwhile, the optic disc cupping had become pathological and glaucomatous visual field loss had progressed from mild loss to very extensive loss within two months.

Since the patient was keen to preserve the remaining vision in this eye, despite advice about a possible risk of extraocular spread, we finally placed a Baerveldt tube in the anterior chamber (Figure 1d and Figure 2). The IOP decreased

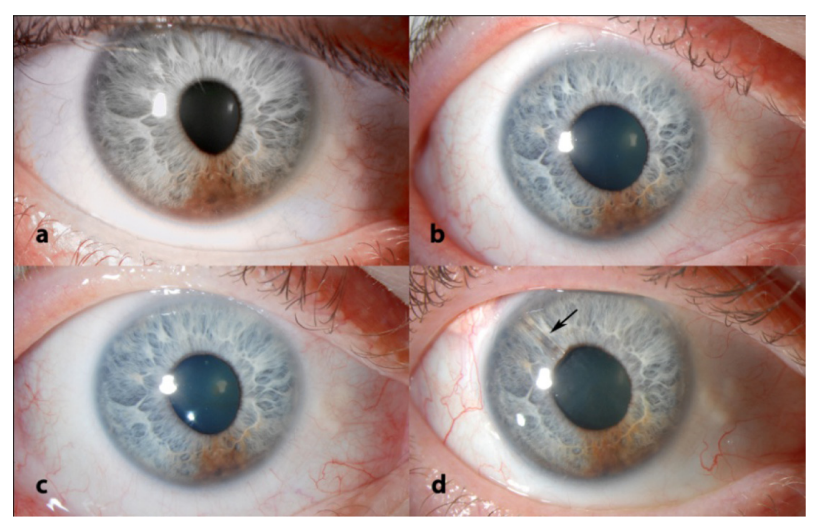

Figure I Slit lap figures. Figure la shows the iris lesion when diagnosed as iris melanoma. Figure Ib shows the lesion after PBT. Figure Ic shows the lesion after PBT. Figure Id shows the Baerveldt tube in the temporal/superior quadrant.

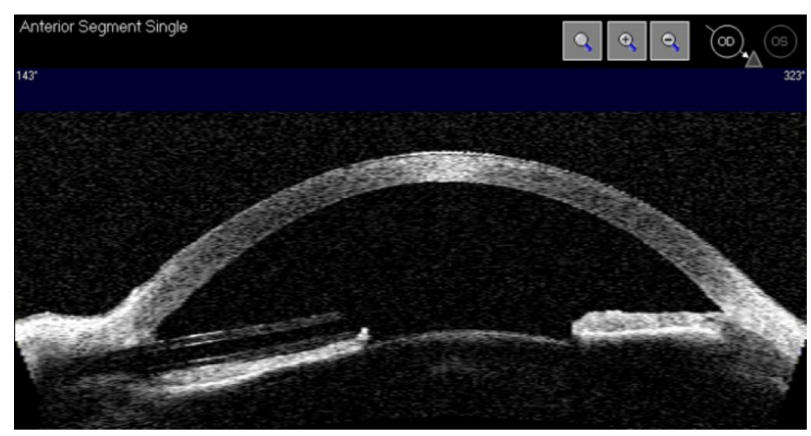

Figure $2 \mathrm{~A}$ Visante OCT scan showing the Baerveldt tube in the anterior chamber to the left.

to $13 \mathrm{mmHg}$. After one year of follow-up, the IOP was stable at $10 \mathrm{mmHg}$ with the additional use of dorzolamide and timolol. The visual field showed no further deterioration. The BCVA was $6 / 15$. The patient declined systemic screening for metastasis; however, he remains under intensive ophthalmic surveillance.

\section{Discussion}

Secondary glaucoma after PBT for iris melanoma can be difficult to control with medical therapy. ${ }^{7}$ We report successful lowering of the IOP in such a case by using a Baerveldt glaucoma implant.

To our knowledge this approach has not been reported previously. As a rule, drainage surgery is avoided after treatment of iris melanoma, probably because of concerns that tumor cells might seed through the drainage fistula and metastasize to other parts of the body. Therefore, we initially attempted to lower the IOP by SLT. Insights from genetic studies on uveal melanomas suggest, however, that these tumors metastasize almost exclusively if they show loss of chromosome $3^{8}$ or class II gene expression profile. ${ }^{9}$ There is growing evidence that metastasis starts at a very early stage, before the patient even presents to the ophthalmologist. ${ }^{10}$ For these reasons, there are now considerable doubts that glaucoma drainage surgery would enhance risks of metastasis spread to the rest of the body by providing an exit route from the eye.

Another concern is that the iris melanoma can recur and seed through the tube into the subconjunctival and orbital tissues. We consider these risks to be small, firstly, because local tumor recurrence is rare after PBT and, secondly, because the tumor was located far from the internal opening of the tube (Figure 1d). In any case, the patient is being monitored closely so that appropriate treatment can be administered without delay in case of re-growth of the tumor. 
Further studies with more patients and long-term follow-up are indicated to evaluate the safety and efficacy of the Baerveldt glaucoma implant for the treatment of secondary glaucoma after PBT for iris melanoma.

\section{Disclosures}

The authors report no conflicts of interest in this work.

\section{References}

1. Henderson E, Margo CE. Iris melanoma. Arch Pathol Lab Med. 2008;132(2):268-272.

2. Shields CL, Shields JA, Materin M, et al. Iris melanoma: risk factors for metastasis in 169 consecutive patients. Ophthalmology. 2001;108(1):172-178.

3. Girkin CA, Goldberg I, Mansberger SL, Shields JA, Shields CL. Management of iris melanoma with secondary glaucoma. J Glaucoma. 2002;11(1):71-74.
4. Rundle P, Singh AD, Rennie I. Proton beam therapy for iris melanoma: a review of 15 cases. Eye. 2007;21(1):79-82.

5. Shields CL, Materin MA, Shields JA, et al. Factors associated with elevated intraocular pressure in eyes with iris melanoma. Br JOphthalmol. 2001;85(6):666-669.

6. Lumbroso-Le Rouic L, Delacroix S, Dendale R, et al. Proton beam therapy for iris melanomas. Eye. 2006;20(11):1300-1305.

7. Damato B, Kacperek A, Chopra M, et al. Proton beam radiotherapy of iris melanoma. Int J Radiat Oncol Biol Phys. 2005;63(1):109-115.

8. Prescher G, Bornfeld N, Hirche H, et al. Prognostic implications of monosomy 3 in uveal melanoma. Lancet. 1996;347(9010): $1222-1225$.

9. Onken MD, Worley LA, Ehlers JP, Harbour JW. Gene expression profiling in uveal melanoma reveals two molecular classes and predicts metastatic death. Cancer Res. 2004;64(20):7205-7209.

10. Eskelin S, Pyrhonen S, Summanen P, Hahka-Kemppinen M, Kivela T. Tumor doubling times in metastatic malignant melanoma of the uvea: tumor progression before and after treatment. Ophthalmology. 2000;107(8):1443-1449.
Clinical Ophthalmology

\section{Publish your work in this journal}

Clinical Ophthalmology is an international, peer-reviewed journal covering all subspecialties within ophthalmology. Key topics include: Optometry; Visual science; Pharmacology and drug therapy in eye diseases; Basic Sciences; Primary and Secondary eye care; Patient Safety and Quality of Care Improvements. This journal is indexed on

Submit your manuscript here: http://www.dovepress.com/clinical-ophthalmology-journal

\section{Dovepress}

PubMed Central and CAS, and is the official journal of The Society of Clinical Ophthalmology (SCO). The manuscript management system is completely online and includes a very quick and fair peer-review system, which is all easy to use. Visit http://www.dovepress.com/ testimonials.php to read real quotes from published authors. 